\title{
Identifying strategies to improve diabetes care in Alberta, Canada, using the knowledge-to-action cycle
}

\author{
Braden Manns MD MSc, Ted Braun MD, Alun Edwards MD, Jeremy Grimshaw MBChB PhD, \\ Brenda Hemmelgarn MD PhD, Don Husereau MSc, Noah Ivers MD MSc, Jeff Johnson PhD, \\ Steve Long BSc MBA, Kerry McBrien MD MPH, Christopher Naugler MD, Peter Sargious MD MPH, \\ Sharon Straus MD MSc, Marcello Tonelli MD SM, Andrea C. Tricco PhD, Catherine Yu MD MHSc; \\ for the Alberta Innovates - Health Solutions Interdisciplinary Chronic Disease Collaboration
}

\section{Abstract}

Background: Strategic clinical networks, a recent development in the health system in Alberta, have been charged with bringing together front-line clinicians, researchers and policy-makers to identify variation in clinical care, and to propose standards, pathways and innovative solutions to improve access and quality of care. Here, we describe a collaborative workshop held between researchers and the Obesity, Diabetes and Nutrition Strategic Clinical Network to describe barriers to and facilitators of care for people with diabetes and to identify quality improvement interventions that should be prioritized.

Methods: Through collaboration between health researchers and the strategic clinical network, and using principles of the knowledgeto-action cycle, we identified barriers to and facilitators of diabetes care using data from a patient survey and a provider focus group (5 primary care physicians and 1 diabetes educator). In addition, we identified best evidence from a systematic review of quality improvement initiatives in diabetes. This information was reviewed at a multistakeholder workshop where potential quality improvement initiatives were considered at various service levels.

Results: A pilot survey involving 59 patients with diabetes and a focus group of primary care and allied health care providers identified several important barriers to optimal outcomes in diabetes care, including patient-level financial barriers to care and difficulty navigating the health system. Our collaborative discussion using the knowledge-to-action cycle prioritized feasible, evidence-based interventions to improve outcomes for patients with diabetes, including enabling care by allied health care providers and creating clear care maps and processes for system navigation.

Interpretation: We identified important barriers to achieving optimal outcomes in diabetes that may be overcome through the use of evidence-based quality improvement interventions. As recommended within the knowledge-to-action cycle, future research is required to determine whether program implementation improves outcomes and is cost-effective.

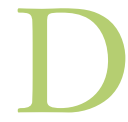

iabetes affects 2.4 million Canadians, including 206000 people in Alberta (as of 2009). ${ }^{1,2}$ Managing the disease and its complications costs the country $\$ 9$ billion each year ( $\$ 1$ billion in Alberta). ${ }^{3}$ Diabetes is the leading cause of kidney failure and a major contributor to vascular disease. ${ }^{4}$ Treatments to reduce complications and cardiovascular events are available, ${ }^{5,6}$ but managing the disease is multifaceted, including lifestyle and behavioural changes. Many patients with diabetes are unable to achieve recommended treatment targets.

Comprehensive care to support behavioural change and optimize disease management can improve clinical outcomes.? Although it is difficult to deliver, such care may be enhanced through multidisciplinary chronic disease management programs. In Alberta, the availability of these programs, and the type of programs offered, depends on where the patient is living (e.g., geographic catchment areas or Alberta Health Services zones) (Box 1). Recent research suggests that care and outcomes for patients with diabetes vary across these zones, ${ }^{10}$ although it is unclear whether this variation is due to differences in patients, the availability of care processes or both. Almost $11 \%$ of Alberta residents with diabetes have acetylated hemoglobin

\section{Competing interests: None declared.}

Disclaimer: Sharon Straus is an associate editor for CMAJ Open and was not involved in the editorial decision-making process for this article.

This article has been peer reviewed.

Correspondence to: Braden Manns, braden.manns@albertahealthservices.ca CMAJ Open 2013.DOI:10.9778/cmajo.20130024 
levels in excess of $10 \%$, with substantial variability noted across the province. ${ }^{1}$

These differences may exist, in part, because primary care networks consisting of groups of family practices (Box 1) are able to set their own strategic priorities. Thus, some networks may more strongly emphasize programming for people with diabetes. In addition, there are no regional or provincial standards for implementing the programs that are delivered. Such choices in approach are left to the providers practising in each network, and previous studies have shown large variation in

\section{Box 1: Diabetes care in Alberta, Canada}

- Within Alberta, inpatient care and many outpatient services are delivered by a single corporation, Alberta Health Services, which was formed in 2008 through provincial legislation that amalgamated numerous smaller health care delivery regions and specialty agencies. Although most diabetes care takes place in the primary care setting, Alberta Health Services offers a variety of programs to patients with diabetes. These services can be offered in several large centres staffed by 1 or more providers, including diabetes nurses, dietitians, pharmacists, psychologists, social workers and physicians (specialists or family physicians). Care centres provide various services, including diabetes management, education, exercise and self-management programs, but the types and breadth of services varies across zones.

- In 2005, in recognition of the need for more coordinated primary care, the provincial health ministry supported the development of a local version of patient-centred medical homes, called Alberta Primary Care Networks. ${ }^{8}$ A primary care network consists of primary care physicians and other health care providers working together to provide care to patients. In addition to typical physician services paid for on a fee-forservice basis, funding is provided to primary care networks (\$62 per enrolled patient/yr) to support activities that fall outside the fee-for-service model. ${ }^{8}$ Although primary care networks may vary in size, they each provide care to about 90000 patients and include an average of 75 primary care physicians across different practices. Currently, there are 41 primary care networks in Alberta, providing care for $70 \%$ of the province's residents. The objectives guiding all primary care networks are similar and include increasing access to primary care, increasing emphasis on care of patients with chronic diseases and improving the coordination of primary health care services with specialist care. Diabetes care has been identified as a priority for most primary care networks. Preliminary evaluation has suggested that primary care networks have led to measurable, albeit small, improvements in health for patients with diabetes. ${ }^{1}$

- In 2011, Alberta Health Services announced the implementation of large-scale quality improvement collaborations, similar to the strategic clinical networks of the United Kingdom, which are intended to identify variation in clinical care and to propose standards, pathways and innovative solutions to improve access, quality and sustainability within the health care system. ${ }^{9}$ These networks are intended to align incentives and accountability for quality improvement initiatives, and to facilitate linkages to research. One of the first strategic clinical networks to be established was the Obesity, Diabetes, and Nutrition Strategic Clinical Network in June 2012, with a mandate that included improving outcomes and the access to and quality and cost-effectiveness of care in diabetes. the types of quality improvement initiatives offered..$^{10}$ This is important since a recent systematic review has shown significant variation in the effectiveness of different types of quality improvement initiatives in diabetes (including chronic disease management programs). ${ }^{11}$

Given the known variation in outcomes seen among patients with diabetes, ${ }^{10}$ the Interdisciplinary Chronic Disease Collaboration, a group of health services researchers and decision-makers, and the Obesity, Diabetes and Nutrition Strategic Clinical Network planned a series of activities to examine the possible causes of suboptimal outcomes and the variation in observed measures in the quality of diabetes care, with the aim of identifying opportunities, barriers and strategic directions for future action. We describe these activities, as well as a collaborative workshop that was held between researchers and the Obesity, Diabetes and Nutrition Strategic Clinical Network. The main foci of the workshop were to describe barriers to and facilitators of care for people with diabetes, and to identify quality improvement interventions that should be prioritized to overcome these barriers.

\section{Methods}

\section{Framework of activities}

The activities we performed followed the principles of the knowledge-to-action cycle (Figure 1) ${ }^{12}$ which emphasizes the critical importance of developing interventions through a conscientious examination of health needs, current knowledge, barriers and facilitators, and tailoring evidence-based interventions to the local context.

\section{Preparatory work done in advance of the workshop}

In accordance with the knowledge-to-action cycle, we completed several activities to prepare for the workshop. We identified gaps in care for patients with diabetes in Alberta, ${ }^{1}$ noting variation across geographic zones. We performed a systematic review of randomized clinical trials for 11 defined quality improvement strategies for the outpatient management of diabetes in adults. ${ }^{11}$

We assessed barriers to and facilitators of care by surveying patients living with diabetes from primary care offices in Calgary, Alberta, in April 2012. Our questions were taken from validated surveys ${ }^{13-16}$ and were based on the following previously identified issues related to diabetes care: access to care; the relevance of cost, knowledge, skills and access to health information; and information sources for diabetes (Appendix 1, available at www.cmajopen.ca/content/1/4/E142/suppl/DC1). In addition, we hosted a focus group of Alberta-based primary care providers using a purposive sample of 5 primary care providers and 1 diabetes nurse educator to identify relevant behaviours and barriers to optimizing care in diabetes. ${ }^{17}$ Ethics approval was received from the Conjoint Health and Research Ethics Review Board at the University of Calgary.

\section{Attendees and workshop activities}

A multistakeholder workshop was held in Calgary, Alberta, on Apr. 30 and May 1, 2012. Attendees included 13 academic 
leaders, 11 health care providers ( 8 physicians, 1 dietitian, 1 pharmacist and 1 nurse) and 17 policy-makers. Consistent with the knowledge-to-action cycle (Figure 1), we first presented evidence showing substantial variation in care among quality indicators (e.g., proportion of patients with acetylated hemoglobin $>10 \%$; proportion of patients appropriately using statins) across geographic areas within Alberta ("Identifying the problem").

Next, we presented best evidence, including the results of a recent systematic review of quality improvement initiatives (which noted substantial variation in the effectiveness of quality improvement initiatives $)^{11}$ and the highlights from the
2013 Canadian Diabetes Association guidelines ("Adapting knowledge to local context"). ${ }^{18}$ We then presented data from the local survey and focus groups, in addition to data from 3 Ontario-based studies involving multidisciplinary groups (which included nurses, dietitians, pharmacists, social workers, physicians and other primary care providers $[n=101]$, and patients $[n=25])$, to outline barriers to and facilitators of care in diabetes ("Assessing barriers to knowledge use").

Our discussion focused on what quality-of-care interventions could be prioritized to overcome patient, provider and health system barriers ("Selecting and tailoring interventions") (Figure 1). After the presentations (available at www.icdc.ca

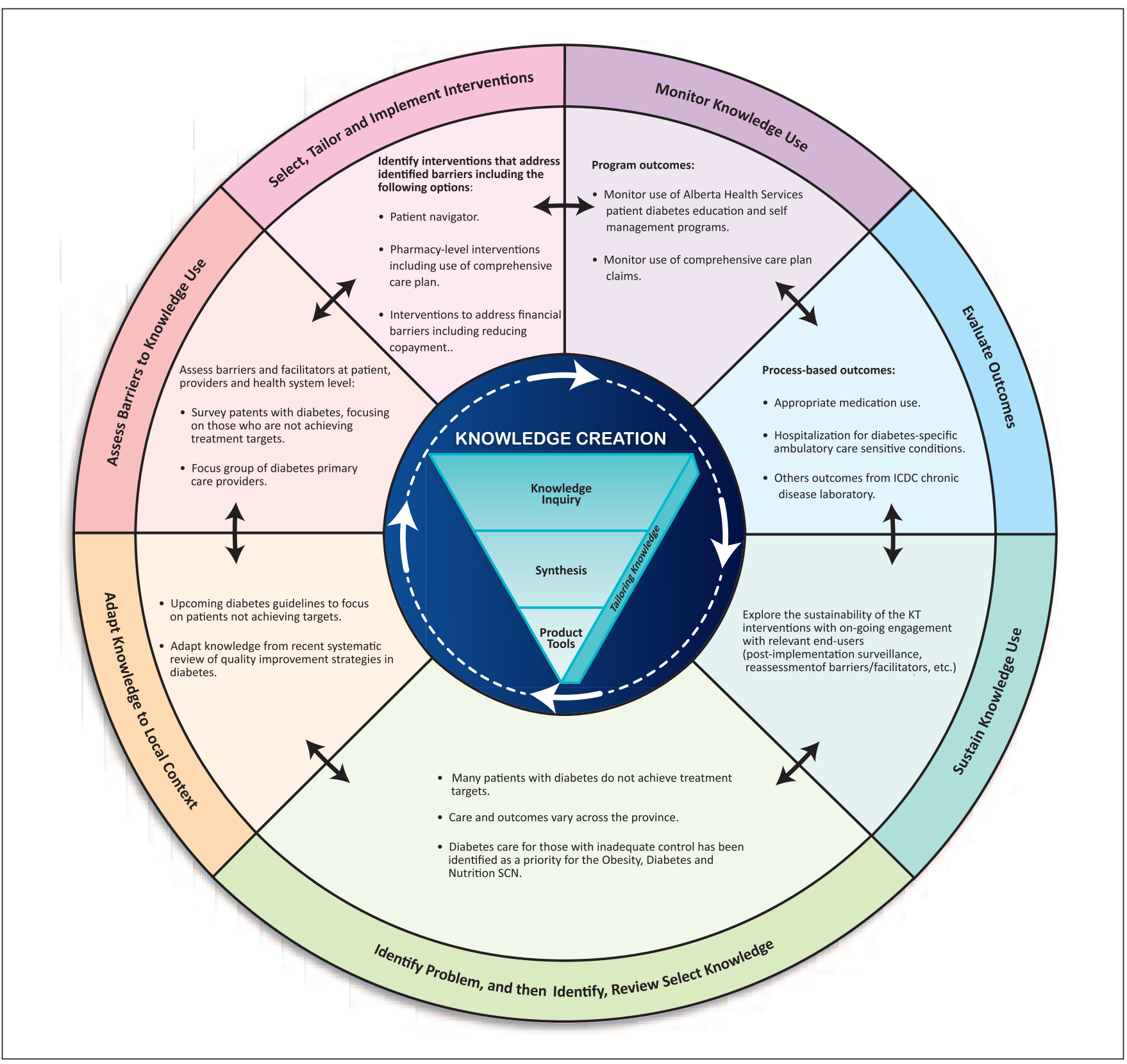

Figure 1: The knowledge-to-action cycle. Adapted from J Contin Educ Health Prof 2006;26:13-24. ${ }^{12}$ ICDC = Interdisciplinary Chronic Disease Collaboration, $\mathrm{KT}$ = knowledge transfer, $\mathrm{SCN}$ = strategic clinical network. 
/images/Diabetes_workshop_ICDC-SCN-_FINAL_October _2012-_added_Libin.pdf), participants were divided into smaller working groups, with academic leaders, clinicians and policy-makers distributed evenly across the groups, to discuss the following topics: how to identify patients with diabetes who need intervention; what interventions should be provided and to whom; how to set standards for care; and how to track the effectiveness of changes in clinical care, including identifying what outcomes are relevant, what factors are measureable and what data sources are available. The agenda for the workshop is listed in Appendix 2 (available at www.cmaj open.ca/content/1/4/E142/suppl/DC1).

\section{Results}

\section{Barriers and facilitators at the patient level}

Of the 59 respondents to the patient survey, $18(30.6 \%)$ were 65 years of age and older, $23(39.0 \%)$ used insulin, and 27 $(45.8 \%)$ had diabetes for more than 5 years (Table 1$)$. Although 55 respondents (93.2\%) identified their family physician as their main health care provider, 20 (33.9\%) of patients identified a diabetes nurse, $17(28.8 \%)$ identified a specialist, 15 (25.4\%) identified a dietician and $10(16.9 \%)$ identified a pharmacist as being involved with their care. Thirteen respondents $(22.0 \%)$ reported that they disagreed or strongly disagreed with the statement that their physicians thought their blood glucose levels were well controlled, and $23(39.0 \%)$ reported that their blood pressure remained above their physicians' targets, identifying these patients as having an increased risk for future adverse events.

Although lifestyle changes were reportedly recommended to almost all of the survey respondents (53 of 59 [89.8\%]), only $29(49.1 \%)$ reported that they were able to implement most of the changes. Reasons for these challenges included difficulties in following a healthy diet, incorporating exercise and maintaining motivation, in addition to the cost of managing diabetes (Figure 2). Other barriers patients identified as important were costs associated with drugs and diabetes supplies (whether patients had insurance) and the ability to access a specialist physician in a timely fashion (Figure 3 ).

\begin{tabular}{|c|c|}
\hline Characteristic & $\begin{array}{l}\text { No. of respondents (\%) } \\
\qquad n=59\end{array}$ \\
\hline \multicolumn{2}{|l|}{ Age, yr } \\
\hline$<50$ & $16(27.1)$ \\
\hline $50-64$ & $25(42.3)$ \\
\hline $65-74$ & $9(15.3)$ \\
\hline$\geq 75$ & $9(15.3)$ \\
\hline Using insulin & $23(40.0)$ \\
\hline \multicolumn{2}{|l|}{ No. of years with diabetes } \\
\hline$<1$ & $11(18.6)$ \\
\hline 1 to 5 & $20(33.9)$ \\
\hline$>5$ & 27 (45.9) \\
\hline Drug insurance & 53 (89.9) \\
\hline \multicolumn{2}{|l|}{ Team members involved in managing patient's diabetes } \\
\hline Family physician & $55(93.2)$ \\
\hline Specialist & $17(28.8)$ \\
\hline Diabetes nurse & 20 (33.9) \\
\hline Nurse practitioner & (8.5) \\
\hline Dietitian & $15(25.4)$ \\
\hline Pharmacist & $10(16.9)$ \\
\hline Other & $1 \quad(1.7)$ \\
\hline $\begin{array}{l}\text { Health care team has recommended lifestyle changes to manage } \\
\text { diabetes }\end{array}$ & $53(89.8)$ \\
\hline Patient was able to make most or all of the changes & $29(49.1)$ \\
\hline Patient was able to make a few of the changes & $23(39.0)$ \\
\hline Patient was unable to make any of the changes & $(1.7)$ \\
\hline $\begin{array}{l}\text { Disagree or strongly disagree that their physician thinks their } \\
\text { glucose levels are well-controlled }\end{array}$ & $13(22.0)$ \\
\hline $\begin{array}{l}\text { Have been told by their physician that their blood pressure is higher } \\
\text { than normal }\end{array}$ & $23(39.0)$ \\
\hline
\end{tabular}




\section{Provider and health system barriers}

Feedback from the provider focus group showed that providers felt sufficient clinical information was available to guide care for people with diabetes, but they noted frustration over conflicting clinical practice guidelines. The focus group also described barriers related to a lack of communication across specialties and a lack of information about effective interprofessional collaboration. The focus group suggested that a lack of time to spend with patients was an important barrier, and that sufficient resources and access to allied health care providers (e.g., pharmacists, nurses) could alleviate this concern. These concerns were affirmed by workshop participants (Table 2).

Several structural or system-level barriers were identified,

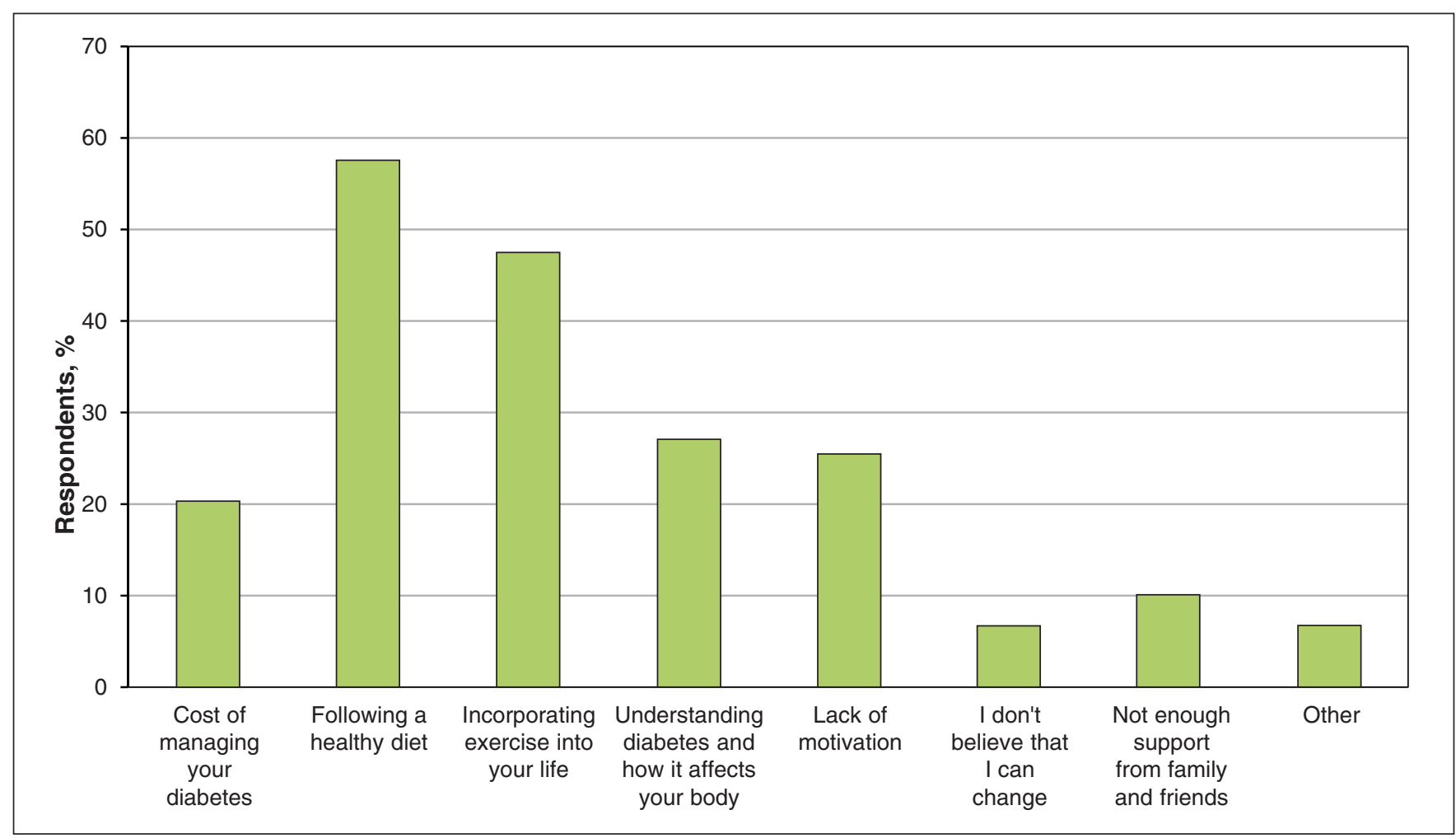

Figure 2: The frequency of barriers to lifestyle changes identified by patients with diabetes $(n=59)$. Proportions add to more than $100 \%$ because patients could identify more than 1 issue.

Making an appointment to see my family doctor in a timely manner

Being unable to access a physician specialist in a timely manner

Having difficulty getting to a medical office, clinic or laboratory

Having difficulty paying for the cost of diabetes-related medication or supplies

Being unsure about who to see about a diabetes-related issue

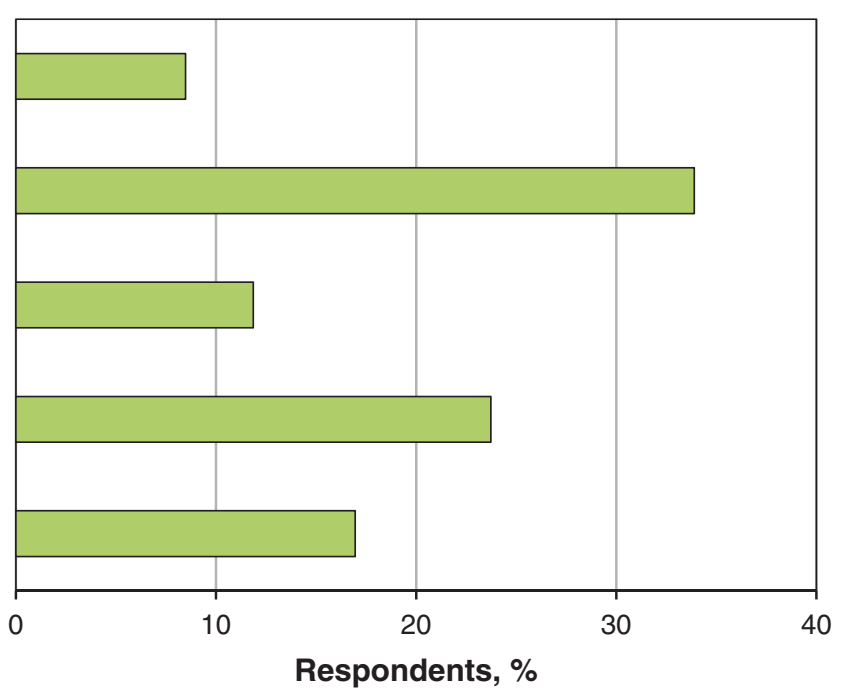

Figure 3: The proportion of people with diabetes who face moderate or substantial barriers relevant to their care $(n=59)$. 
reflecting concerns from patients and providers. Workshop participants believed inadequate numbers of available providers, who in turn may lack an adequate breadth of scope in their roles, and a lack of coordination, navigation through explicit standards and clear delineation of roles and responsibilities within the system were important barriers to optimal outcomes (Table 2).

\section{Proposed interventions}

Several evidence-based interventions were discussed to address identified barriers (Table 3). Workshop participants suggested that improving adherence to drugs and supplies could be facilitated by lowering copayments or providing reimbursement for drugs where none is available. ${ }^{19}$ There was discussion about the role that pharmacists might play in improving drug use through payment to pharmacists for developing comprehensive care plans based on evidence of improved quality of primary care.

Participants also noted that the need for improved navigation and timely access could be addressed by implementing a system of case management, possibly combined with facili-

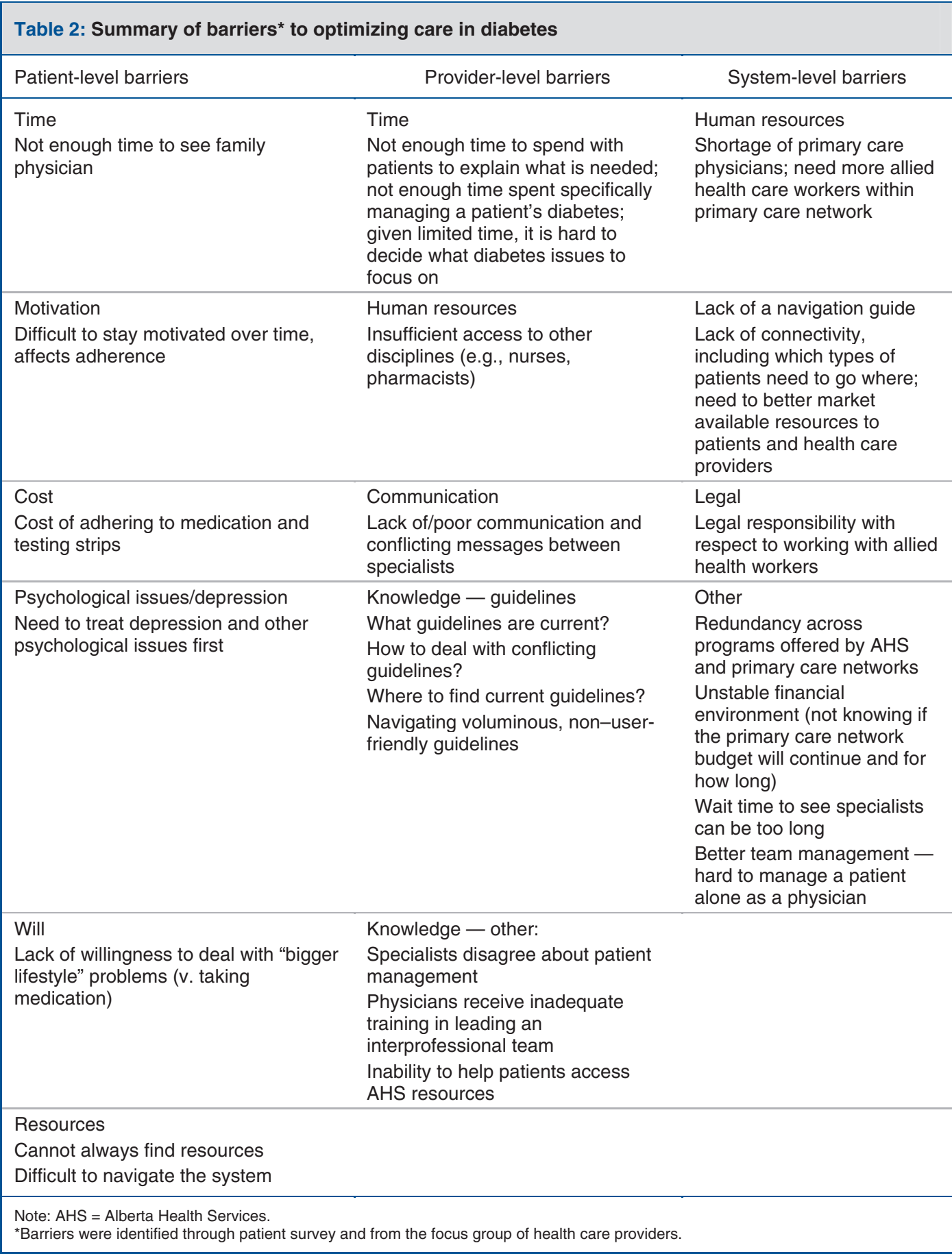


tated relay (where patients are prompted to relay information to their physician with the goal of facilitating a change in treatment). ${ }^{11}$ Because all laboratory results relevant to diabetes management are available electronically, patients (specifically those at high-risk of complications) could be identified and referred to an appropriate resource, and subsequently tracked to assess any improvement in their condition. This idea was felt to be particularly feasible in primary care networks that could implement standard system-wide approaches and care pathways.

Workshop participants emphasized the importance of considering heterogeneity of response and cost-effectiveness of quality improvement strategies — that is, looking beyond average measures of effectiveness. Although patient-mediated interventions (e.g., self-management) appeared moderately effective across all subtypes of patients, larger effects have been observed for team changes and case management when baseline acetylated hemoglobin levels were higher than $8 \%$ and systolic blood pressure was greater than $140 \mathrm{~mm} \mathrm{Hg}{ }^{11}$ Because case management and team changes are more expensive interventions, workshop participants noted that they should be tailored to patients at higher risk of complications, whereas patient-mediated (less expensive) interventions (e.g., patient education, patient reminders, self-management) might be appropriate for wider implementation. ${ }^{11}$

\section{Interpretation}

In preparation for the workshop, we noted substantial variation in the care and outcomes of patients with diabetes, summarized the effectiveness of quality improvement initiatives and identified several important patient-, provider- and system-level barriers to optimal care and outcomes for patients in Alberta. We identified cost-related barriers in addition to issues in navigating the health system. Our discussion identified several feasible, evidence-based initiatives that might improve care and outcomes for patients with diabetes, including enabling care by allied health care providers, such as pharmacists, and creating clear care maps to ensure providers and patients understand how to navigate the programs and services offered. One of the interventions identified has already been implemented across the province (the provision of a reimbursement code for pharmacists to provide comprehensive care for patients with chronic diseases), and one has been announced but has not yet been implemented (universal drug insurance for Alberta residents) (Table 3). Given the timing of these policies, it is uncertain whether the workshop had an effect on their development and implementation, but there is clearly mutual interest in their rigorous evaluation. Noting that the current lack of clear standards and pathways is perceived as creating barriers both for providers and for patients,

Table 3: Proposed solutions to improve outcomes in patients with diabetes in Alberta

\begin{tabular}{|c|c|c|c|}
\hline Issue & Barrier level & Proposed solution & Evidence \\
\hline \multirow[t]{3}{*}{ Costs of drugs and supplies } & \multirow[t]{3}{*}{ Patient } & $\begin{array}{l}\text { New program to pay for test strips for patients } \\
\text { taking insulin }\end{array}$ & \multirow[t]{3}{*}{ Austvoll-Dahlgren et al. ${ }^{19}$} \\
\hline & & $\begin{array}{l}\text { Potential reductions in copayments for some } \\
\text { diabetes drugs }\end{array}$ & \\
\hline & & $\begin{array}{l}\text { Provision of insurance for uninsured people with } \\
\text { diabetes }^{*}\end{array}$ & \\
\hline $\begin{array}{l}\text { Difficult to stay motivated, follow } \\
\text { a healthy diet }\end{array}$ & Patient & $\begin{array}{l}\text { Patients at low risk } \\
\text { Create a standard care pathway for primary care } \\
\text { networks involving patient education and } \\
\text { promoting self-management } \\
\text { Patients at high risk } \\
\text { Case management and multidisciplinary teams }\end{array}$ & Ticco et al. ${ }^{11}$ \\
\hline Timely access to providers & $\begin{array}{l}\text { Patient and } \\
\text { provider }\end{array}$ & $\begin{array}{l}\text { Increased use of "navigators" to facilitate referral of } \\
\text { patients to appropriate resources }\end{array}$ & $\begin{array}{l}\text { Ticco et al. }{ }^{11} \\
\text { Manderson et al. }{ }^{20}\end{array}$ \\
\hline $\begin{array}{l}\text { Lack of resources/allied health } \\
\text { providers }\end{array}$ & Provider & $\begin{array}{l}\text { Pay pharmacists to develop comprehensive care } \\
\text { plans in collaboration with multidisciplinary } \\
\text { physician-led teams } \\
\text { Increase scope of practice for allied health } \\
\text { practitioners for patients at highest risk }\end{array}$ & Ticco et al. ${ }^{11}$ \\
\hline $\begin{array}{l}\text { Need for improved } \\
\text { communication and system } \\
\text { navigation/lack of consistent } \\
\text { guidance and standards }\end{array}$ & Provider & $\begin{array}{l}\text { Develop an enhanced care map that is fully } \\
\text { integrated within electronic medical records }\end{array}$ & Shojania et al. ${ }^{21}$ \\
\hline $\begin{array}{l}\text { Lack of allied care provider } \\
\text { accountability }\end{array}$ & System & $\begin{array}{l}\text { Enhance the role for pharmacists, including the } \\
\text { ability to write prescription refills, administer } \\
\text { injections and modify prescriptions } \dagger\end{array}$ & Ticco et al. ${ }^{11}$ \\
\hline
\end{tabular}


participants thought that the Obesity, Diabetes and Nutrition Strategic Clinical Network could serve as a model to address such barriers.

A previous systematic review suggested that stronger and more effective coordination of primary care activities requires reforms in governance and funding, and that more comprehensive reforms lead to better health outcomes and higher patient satisfaction..$^{22}$ This finding is also apparent in substantive evidence that aligned incentives and collaboration of researchers and policy-makers are required for effective implementation and uptake of quality improvement initiatives. ${ }^{23}$ With the introduction of strategic clinical networks in Alberta, there is an opportunity to develop evidence-based initiatives that can be implemented, monitored, measured and sustained.

Current evidence supporting the effectiveness of largescale quality improvement collaborations is limited. ${ }^{24}$ The concept of strategic clinical networks in Alberta is similar to that of managed clinical networks in the United Kingdom ${ }^{25}$ and the newly introduced National Health Service Commissioning Board Strategic Clinical Networks, ${ }^{9}$ where coordination across existing health service and disciplinary boundaries created historical barriers to the effective implementation of national guidelines and quality of care. Strategic and managed clinical networks emphasize interdisciplinary links to improve the quality of patient care, and combine fiscal and human resource responsibilities and clinical, research and development expertise under a single accountable structure. An independent evaluation of a managed clinical network in Scotland suggested improvements in processes and outcomes for patients with diabetes after its implementation. ${ }^{26}$ The evaluation also suggested that the lack of patient and managerial involvement during the network's formative years was problematic, and a key to its success was effective engagement across specialties. ${ }^{26}$

\section{Limitations}

Given our short timelines before the workshop, we relied on a brief survey that included some questions that had not undergone formal validation. In addition, our sample of patients and providers was small, and all participants were from an urban setting. These factors limit the generalizability of our findings. Although it is possible that a more thorough investigation of patient and provider opinions may identify other important barriers and facilitators, time and resource limitations dictated a pragmatic approach. As part of the 2011 Canadian Community Health Survey, additional work in this area will be informed by a more comprehensive and larger survey to evaluate economic barriers to care, insurance status and other patient-, provider- and system-level barriers to care in nearly 2000 people with chronic ilnesses. ${ }^{16}$

We proposed standards for care pathways and quality improvement initiatives when no formal mechanism for coordinating such initiatives across primary care networks currently exists. Although we hope that strategic clinical networks can help to achieve these objectives, a lack of high-level coordination may introduce diseconomies of scale and increase the risk that scarce health resources will be used less efficiently as multiple stakeholders involved in diabetes care implement different programs with different approaches that target inconsistent standards. Formal implementation and evaluation of strategic initiatives are still required to complete the knowledge-to-action cycle.

\section{Conclusion}

We identified important barriers to achieving optimal outcomes in patients with diabetes that may be overcome using evidence-based quality improvement interventions. Our experience suggests that the Canadian Institutes of Health Research knowledge-to-action cycle, coupled with necessary considerations for health care change, can be successfully applied to developing priorities for quality improvement collaborations for diabetes care and, potentially, to improve the management of other chronic diseases.

Affiliations: Departments of Medicine (Manns, Edwards, Hemmelgarn, Sargious); Community Health Sciences (Manns, Hemmelgarn); and Interdisciplinary Chronic Disease Collaboration (Manns, Braun, Hemmelgarn, McBrien, Tonelli); Libin Cardiovascular Institute and Institute for Population Health (Manns, Hemmelgarn), University of Calgary, Calgary, Alta.; Department of Family Medicine (Braun), Alberta Health Services, Calgary, Alta.; Obesity, Diabetes and Nutrition Strategic Clinical Network (Edwards, Johnson), Alberta Health Services, Calgary, Alta.; Department of Epidemiology and Community Medicine (Grimshaw, Husereau), University of Ottawa, Ottawa, Ont.; Department of Family Medicine (Ivers), Women's College Hospital; and Department of Family and Community Medicine (Ivers), University of Toronto, Toronto, Ont.; Department of Public Health Sciences (Johnson), University of Alberta, Edmonton, Alta.; Alberta Health (Long), Edmonton, Alta.; Departments of Family Medicine (McBrien); Pathology and Laboratory Medicine (Naugler), University of Calgary, Calgary, Alta.; Calgary Laboratory Services (Naugler), Calgary, Alta.; Department of Medicine (Straus, Tricco, Yu), University of Toronto, Toronto, Ont.; Li Ka Shing Knowledge Institute (Straus, Tricco, Yu), St. Michael's Hospital, University of Toronto, Toronto, Ont.; Department of Medicine (Tonelli), University of Alberta, Edmonton, Alta.

Contributors: Braden Manns, Ted Braun, Alun Edwards, Brenda Hemmelgarn and Marcello Tonelli planned and performed the preparatory work, including the analysis and interpretation of data, in advance of the workshop. All of the authors contributed substantially to conception and design of the workshop, including the analysis and interpretation of data reviewed at the workshop. All of the authors drafted or revised the article critically for important intellectual content and approved the final version submitted for publication.

Funding: This research was supported by an interdisciplinary team grant from Alberta Innovates - Health Solutions, the Interdisciplinary Chronic Disease Collaboration and the Canadian Institutes of Health Research (CIHR) (grants no. 238543 and 276737), and by an unrestricted funding grant from the Obesity, Diabetes and Nutrition Strategic Clinical Network. Dr. Tonelli, Dr. Johnson, Dr. Hemmelgarn and Dr. Manns are supported by Alberta Innovates - Health Solutions (formerly Alberta Heritage Foundation for Medical Research) salary awards. Dr. Ivers is supported by a CIHR Fellowship award. Dr. McBrien was supported by an Alberta Innovates Health Solutions Clinician Fellowship award. Dr. Grimshaw, Dr. Straus, Dr. Johnson and Dr. Tonelli are supported by Canada Research Chairs. Dr. Manns, Dr. Edwards, Dr. Sargious, Dr. Hemmelgarn and Dr. Tonelli were supported by an alternative funding plan from the Government of Alberta, The University of Alberta and the University of Calgary.

The sponsors of the study had no role in its design, the collection, analysis or interpretation of the data or the writing of this report.

Supplemental information: For reviewer comments and the original submission of this manuscript, please see www.cmajopen.ca/content /1/4/E142/suppl/DC1 


\section{References}

1. Manns BJ, Tonelli M, Zhang J, et al. Enrolment in primary care networks: impact on outcomes and processes of care for patients with diabetes. CMAJ 2012;184:E144-52.

2. Johnson JA. Alberta diabetes atlas 2009. In: Johnson JA, editor. Edmonton (AB): Institute of Health Economics; 2009.

3. Simpson SH, Corabian P, Jacobs $\mathrm{P}$, et al. The cost of major comorbidity in people with diabetes mellitus. CMA7 2003;168:1661-7.

4. Diabetes in Canada: facts and figures from a public bealth perspective. Ottawa (ON): Public Health Agency of Canada; 2011.

5. Gray A, Raikou M, McGuire A, et al. Cost effectiveness of an intensive blood glucose control policy in patients with type 2 diabetes: economic analysis alongside randomised controlled trial (UKPDS 41). United Kingdom Prospective Diabetes Study Group. BM7 2000;320:1373-8.

6. Cost-effectiveness of intensive glycemic control, intensified hypertension control, and serum cholesterol level reduction for type 2 diabetes. $7 A M A 2002$; 287:2542-51.

7. Gaede P, Vedel P, Larsen N, et al. Multifactorial intervention and cardiovascular disease in patients with type 2 diabetes. N Engl f Med 2003;348:383-93.

8. Alberta Health Services. Strategic clinical. Available: www.albertahealthservices .ca/scn.asp (accessed 2013 Oct. 31).

9. Strategic clinical networks. England: National Health Service; 2012. Available: www.commissioningboard.nhs.uk/2012/07/26/strat-clin-networks/ (accessed 2013 Sept. 13).

10. Campbell DJ, Sargious P, Hemmelgarn B, et al. The use of chronic disease management programs for diabetes by Alberta's primary care networks. Can Fam Physician 2013;59:e86-92.

11. Tricco AC, Ivers NM, Grimshaw JM, et al. Effectiveness of quality improvement strategies on the management of diabetes: a systematic review and metaanalysis. Lancet 2012;379:2252-61.

12. Graham ID, Logan J, Harrison MB, et al. Lost in knowledge translation: Time for a map? 7 Contin Educ Health Prof 2006;26:13-24.

13. Anderson RM, Fitzgerald JT, Gruppen LD, et al. The Diabetes Empowerment Scale - Short Form (DES-SF). Diabetes Care 2003;26:1641-2.
14. Anderson RM, Funnell MM, Arnold MS, et al. Assessing the cultural relevance of an education program for urban African Americans with diabetes. Diabetes Educ 2000;26:280-9.

15. Anderson RM, Funnell MM, Fitzgerald JT, et al. The Diabetes Empowerment Scale: a measure of psychosocial self-efficacy. Diabetes Care 2000;23:739-43.

16. Barriers to care for people with chronic health conditions (BCPCHC) survey Calgary (AB): Interdisciplinary Chronic Disease Collaboration; 2012. Available: www.icdc.ca/images/BCPCHC_Phase_2_Survey_Working_Paper-_Mar_19 _2013.pdf (accessed 2013 July 18).

17. Michie S, Johnston M, Abraham C, et al. Making psychological theory useful for implementing evidence based practice: a consensus approach. Qual Saf Health Care 2005;14:26-33.

18. Canadian Diabetes Association Clinical Practice Guidelines Expert Committee. Canadian Diabetes Association 2013 clinical practice guidelines for the prevention and management of diabetes in Canada. Can 7 Diabetes 2013;37(Suppl 1):S197-212.

19. Austvoll-Dahlgren A, Aaserud M, Vist G, et al. Pharmaceutical policies: effects of cap and co-payment on rational drug use. Cochrane Database Syst Rev 2008; (1):CD007017.

20. Manderson B, McMurray J, Piraino E, et al. Navigation roles support chronically ill older adults through healthcare transitions: a systematic review of the literature. Health Soc Care Community 2012;20:113-27.

21. Shojania KG, Jennings A, Mayhew A, et al. The effects of on-screen, point of care computer reminders on processes and outcomes of care. 2009;(3):CD001096.

22. Powell Davies G, Williams AM, Larsen K, et al. Coordinating primary health care: an analysis of the outcomes of a systematic review. Med 7 Aust 2008; 188 (Suppl 8)S65-8.

23. Innvaer S, Vist G, Trommald M, et al. Health policy-makers' perceptions of their use of evidence: a systematic review. 7 Health Serv Res Policy 2002;7:239-44.

24. Schouten LM, Hulscher ME, Van Everdingen JJ, et al. Evidence for the impact of quality improvement collaboratives: systematic review. BMF 2008;336:1491-4.

25. Lega F, Sartirana M. Managed clinical networks: scope, evidence and feasibility. Int 7 Clin Pract 2011;65:725-7.

26. Greene A, Pagliari C, Cunningham S, et al. Do managed clinical networks improve quality of diabetes care? Evidence from a retrospective mixed methods evaluation. Qual Saf Health Care 2009;18:456-61. 